NASA Technical Memorandum 107000

AIAA-95-2801

\title{
Preliminary Assessment of Combustion Modes for Internal Combustion Wave Rotors
}

\author{
M. Razi Nalim \\ Lewis Research Center \\ Cleveland, Ohio
}

Prepared for the

31st Joint Propulsion Conference and Exhibit cosponsored by AIAA, ASME, SAE, and ASEE San Diego, California, July 10-12, 1995

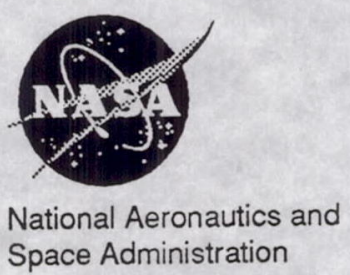

Space Administration 


\title{
PRELIMINARY ASSESSMENT OF COMBUSTION MODES FOR INTERNAL COMBUSTION WAVE ROTORS
}

\author{
M. Razi Nalim" \\ National Research Council \\ NASA Lewis Research Center \\ Cleveland, Ohio
}

\begin{abstract}
Combustion within the channels of a wave rotor is examined as a means of obtaining pressure gain during heat addition in a gas turbine engine. Several modes of combustion are considered and the factors that determine the applicability of three modes are evaluated in detail: premixed autoignition/detonation, premixed deflagration, and non-premixed compression ignition. The last two will require strong turbulence for completion of combustion in a reasonable time in the wave rotor. The compression/autoignition modes will require inlet temperatures in excess of $1500 \circ \mathrm{R}$ for reliable ignition with most hydrocarbon fuels; otherwise, a supplementary ignition method must be provided. Examples of combustion mode selection are presented for two core engine applications that had been previously designed with equivalent 4-port wave rotor topping cycles using external combustion.
\end{abstract}

\section{INTRODUCTION}

The internal combustion wave rotor is a promising means of pressure-gain combustion. This concept, which approaches the thermodynamic ideal of constant-volume combustion within a steady-flow engine flow path, can provide significant enhancement of gas turbine engine performance and can reduce $\mathrm{NO}_{x}$ emissions.

The possibility of constant-volume heat addition, with pressure gain instead of pressure loss, has been a long-sought ideal in the design of gas turbines. Indeed, the earliest working gas turbines had constant-volume or pulsating combustion chambers ${ }^{1}$. The difficulty of analyzing the flow in these devices, and the non-steady flow they presented to the turbine, prevented them from competing with the simpler but less efficient steady-flow combustor. Over the years, a variety of methods have been investigated for pressure-gain combustion or compound cycle arrangements with substantially steady flow to the turbine. These include pulse or valved combustors, detonation-wave combustors, wave rotors, and reciprocating piston engines ${ }^{2,3}$. Figure 1 includes a schematic of the concept and a T-S diagram which shows that constant-volume heat addition (2-3), yields a cycle with greater potential work output (3-4) than a conventional cycle $\left(1-2-3^{\prime}-4^{\prime}\right)$ with the same peak cycle temperature (TIT).

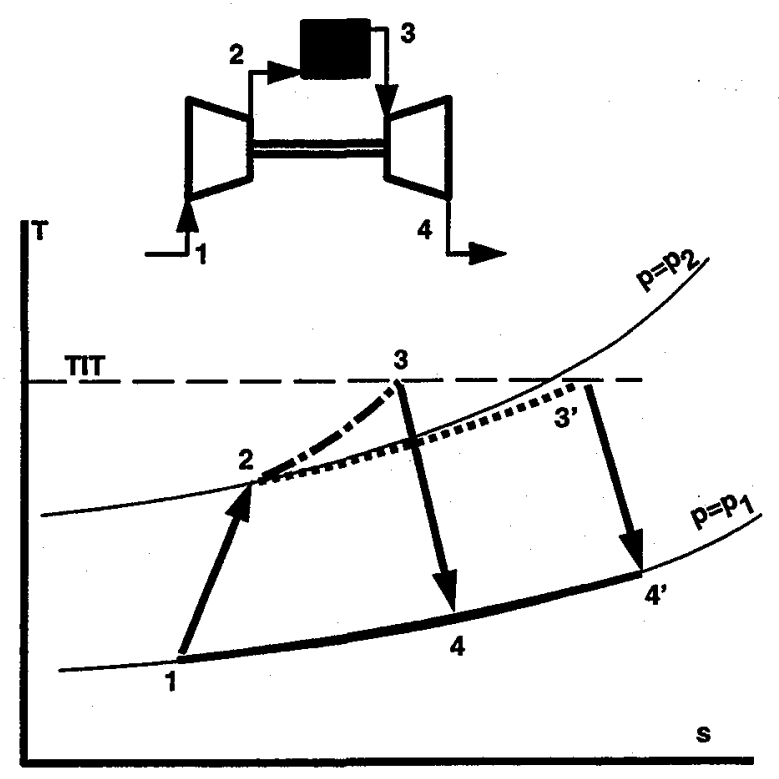

Figure 1. Pressure gain combustion 
The wave rotor arguably offers the closest viable approach to this thermodynamic ideal. On the one hand, simple pulse combustors have passive or no valving to control the flow, but have limited pressure gain potential. On the other hand, piston machines offer tight flow control and high pressure ratios, but are mechanically complex, bulky, and heavy. A well-designed wave rotor can provide large-amplitude pressure waves and active flow control, and will be a light, compact, low-loss device with a single low-cost moving part.

\section{Wave Rotor Background}

The wave rotor is a device that utilizes unsteady waves to exchange energy directly between fluids. It consists of a number of channels arranged about an axis; by rotation the ends of the channels are periodically connected to high and low pressure manifolds which generate and utilize waves in the channels. The flow in the manifolds is steady, and is directed to other steady flow components. An important feature is that as gases of a wide range of temperature flow through the rotor, the channel walls experience a mean temperature that is lower than the highest gas temperature. Rotational speed is low relative to turbomachines, and the geometry usually simpler. The thermal/structural design and materials issues are expected to be less difficult.

Of many proposed applications ${ }^{4}$ the most successful include the Brown Boveri Comprex supercharger for diesel engines ${ }^{5}$, and the Cornell Aero Lab wave 'superheater' for hypersonic research ${ }^{6}$. Currently the wave rotor is receiving renewed attention as a means of improving the performance of gas turbine engines by increasing the pressure ratio and the peak cycle temperature beyond the limits of turbomachinery ${ }^{7-9}$.

Wave rotor enhancement of gas turbines can utilize 'external' (i.e. conventional, steady flow) combustion or 'internal' (on-rotor) combustion. This distinction between internal and external combustion is made with reference to the wave rotor; in the thermodynamic sense, combustion is in both cases internal, i.e., within the working fluid. Previous research to apply wave rotors to gas turbines have generally used external combustion ${ }^{4,7-9}$. Compressor discharge air at low pressure is further compressed in the wave rotor channels by compression waves or shock waves generated by hot combustion gases from an external steady flow combustor. The hot gases expand and cool as they are exhausted to the turbine, which therefore operates at a lower temperature than the combustor exit. Thus the wave rotor provides a topping stage to increase the efficiency and power output. The pressure ratio and peak temperature of the engine cycle are increased.

\section{Pressure Gain Combustion in the Wave Rotor}

In an internal combustion wave rotor, combustion occurs within the wave channels, each channel being periodically charged and discharged as it rotates past appropriate inlet and outlet ports. The typical combustion and wave processes are illustrated in the wave rotor sketch in Figure 2. The inlet manifold has been omitted to reveal the inlet port in the stationary end plate.

This concept has the following advantages:

(a) Pressure gain equivalent to or greater than a topping stage wave rotor, but more compact and with less ducting and associated flow losses, since the external combustor is eliminated.

(b) The burned gas begins expanding within the rotor immediately after combustion, minimizing the residence time at peak temperature and associated $\mathrm{NO}_{\mathrm{x}}$ formation.

In common with an external combustion wave rotor, (c) the wave rotor is periodically cooled by the air flow and can tolerate high gas temperature, and (d) it provides precompression of inlet air as it is brought to rest in the channel. This also provides a source of pressurized cooling air for the turbine, without which pressure-gain concepts are impractical.

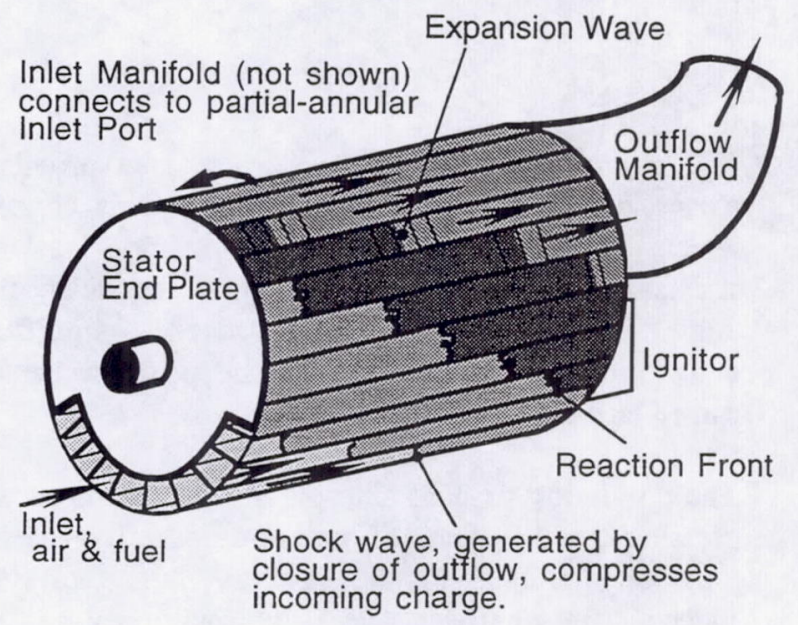

Figure 2. Internal combustion wave rotor sketch 
If successful, this concept could provide a quantum advancement in the performance of combustion engines, relative to the present scope for improvements in conventional gas turbine or reciprocating internal combustion (IC) engines. In a sense it may be said to combine the best of both worlds: the confined-combustion thermodynamic advantage of the IC engine, and the high power/weight advantage of turbine shaft power over piston machinery. The idealized performance of the IC engine cycle, conceived as a sequence of static states, is usually compromised by dynamic effects at high speed operation. In contrast, the wave rotor is designed to exploit dynamic (wave) effects.

Table 1 indicates the pressure rise developed with adiabatic constant volume combustion of hydrogen/air and propane/air mixtures at various initial conditions, calculated using equilibrium chemistry and real gas thermodynamic data. Note that the pressure ratio is strongly influenced by the initial temperature.

For simplicity, the T-S diagram of Figure 1 omitted the dynamic processes of charging and discharging the combustion chamber(s). In reality, the necessity of recharging the channels at the inlet pressure implies that the pressure gain available at the turbine will be less than the ideal constant volume combustion pressure ratio indicated in Table 1 , although still greater than unity. Indeed, it is the wave dynamics of charging and discharging that primarily determine the performance potential of a wave rotor design, irrespective of whether internal or external combustion is used.

The on-rotor combustion process has more in common with IC engine combustion than with conventional gas turbine combustion. A fuel and air mixture in a confined volume must be reacted in a rapid and rather predictable manner, but without structurally unacceptable heat loading, pressure spikes, oscillations or vibrations. Ignition and flame propagation behavior will be dependent on details of fuel properties and/or turbulence properties, which may be difficult to control. The considerable literature on diesel and spark-ignited (SI) combustion and fuel behavior should be helpful, and was consulted extensively for this work. Yet, these phenomena remain poorly understood at the fundamental level, and much of the empirical knowledge available may not be valid beyond the specific engine conditions obtained.
Table 1. Constant volume adiabatic combustion pressure ratio

\begin{tabular}{lllll}
\hline \multirow{2}{*}{$\begin{array}{l}\text { Mixture } \rightarrow \\
\text { Equiv. ratio } \rightarrow\end{array}$} & \multicolumn{2}{c}{$\mathrm{H}_{2} / \mathrm{Air}$} & \multicolumn{2}{c}{$\mathrm{C}_{3} \mathrm{H}_{8} / \mathrm{Air}$} \\
Initial condition $\downarrow$ & 1.0 & 0.5 & 1.0 & 0.5 \\
\cline { 2 - 5 } $536 \circ \mathrm{R}, 1 \mathrm{~atm}$ & 11.3 & 7.4 & 9.3 & 6.3 \\
$1350 \circ \mathrm{R}, 1 \mathrm{~atm}$ & 4.6 & 3.3 & 3.8 & 2.9 \\
$1350 \circ \mathrm{R}, 20 \mathrm{~atm}$ & 4.9 & 3.4 & 4.0 & 2.9 \\
\hline
\end{tabular}

Fast combustion is essential to minimize residence time and rotor size. The typical peak flame speed in an automotive SI engine is of the order of 30-150 $\mathrm{ft} / \mathrm{s}$. In the wave rotor we would like the rate of combustion to be equivalent to a lengthwise flame speed of perhaps $100-500 \mathrm{ft} / \mathrm{s}$ for single-flame premixed combustion, comparable to the wave speeds (typically $1000-2000 \mathrm{ft} / \mathrm{s}$ ), so that the time taken for combustion is not an inordinately large part of the total cycle time. This will require judicious design of the mode of combustion based on fuel properties and the wave rotor inlet conditions over the range of operation of the engine.

\section{Nitrogen Oxides (NO) ) emissions}

Combustion $\mathrm{NO}_{\mathrm{x}}$ emissions are a function of combustion temperature, residence time, and stoichiometry. In a wave rotor, the residence time at high temperature can be kept very short by properly timing the expansion which discharges the channel. The peak cycle temperature (for a homogeneous fluid) will also be somewhat less than for an equivalent-performance topping cycle wave rotor with external constant-pressure combustion. Actual temperatures in any combustor may of course locally exceed this value. It is possible to stratify the charge in the wave rotor inlet for ultra-lean combustion overall and enrichment only at the ignition site, similar to the approach taken for reciprocating engines ${ }^{10,11}$.

A combustion wave rotor could also be designed to incorporate the rich stage of a Rich-Quench-Lean (RQL) low-NO $\mathrm{x}_{\mathrm{x}}$ combustion scheme ${ }^{12,13}$. The RQL scheme requires very quick mixing of hot rich-burn product gases and additional air, in order to go from the rich to the lean condition with minimal time at near-stoichiometric conditions. One current difficulty is that the rich stage combustor liner cannot be cooled by conventional film-cooling with air because of $\mathrm{NO}_{x}$ 
formation. Another drawback is the large pressure drop necessary for injection of air for rapid mixing. A rich-combustion wave rotor can provide: (a) a self-cooled combustion chamber, (b) pressure exchange to bypass air to provide high injection pressure needed for rapid second stage mixing, (c) immediate wave expansion of the rich burn gases, minimizing peak-temperature residence time and $\mathrm{NO}_{x}$ formation, and (d) lower enthalpy of exiting rich product gas by utilizing combustion energy for precompression and bypass compression, thereby reducing stoichiometric temperature and $\mathrm{NO}_{x}$ formation in the mixing-zone.

\section{COMBUSTION MODES}

It is acknowledged that there are many uncertainties about possible reaction initiation, propagation, and extinction mechanisms, and related phenomena. For even the simplest fuels, the chemical mechanism of combustion is complex and not well understood. In addition, molecular diffusion, turbulence, radiation exchange, multi-phase, wall-surface, and catalytic effects may be important.

For the sake of discussion of some of these issues we distinguish among several modes of combustion of fuel and air, involving either premixed or nonpremixed combustion, and different ignition mechanisms. A real combustion system may have features and behavior that combine more than one of these idealized modes. Possible modes for premixed combustion are :

(a) Deflagration, when thermally ignited at one end by a spark, laser, recirculated hot gas, or other means. Laminar flame speed is a very small fraction of the acoustic speed since it depends on molecular diffusion processes -- too slow for lengthwise flame propagation in a wave rotor unless accelerated by turbulence or compression heating, or initiated at multiple ignition sites. As in IC engines, turbulent flame propagation speed will depend principally on turbulence intensity and scales, and on combustion temperature.

(b) Volume mode. This may follow a slow initial deflagration if the (spatially uniform) pressure rise autoignites all the unreacted gas simultaneously. (Predicted for Lewis number less than unity, under certain conditions. ${ }^{14}$ ) The delay time may be excessive or inconsistent for our purpose, making the 'explosion' unreliable. (c) Shock-wave compression ignition followed by a reaction front. This will be achievable with sufficiently high initial temperature, and the reaction timescale will be short. The reaction will strengthen and accelerate the shock. It may be a 'fast flame'15 (slower than the shock), or develop into a detonation.

(d) Self-sustained detonation, initiated either by transition from a deflagration (unlikely for typical channel length), or by shock ignition, or another direct method.

Non-premixed combustion may be treated as a separate mode:

(e) Auto-ignited (or compression-ignited) when fuel is injected into air at (or immediately compressed to) sufficiently high temperature, as in a diesel IC engine. Some of the fuel and oxygen mix before autoignition, and are then rapidly consumed; the remainder react at a rate determined by mixing processes. Turbulent mixing will be essential for fast burn.

Attention will be focused on three of the above modes which are considered most feasible and controllable: (a), (c), and (e). The shock-ignition case of mode (d) is treated as a subset of (c).

The unsteady flow process within the wave rotor is best illustrated by a wave diagram. This may be viewed as an $x-t$ diagram which is a time-history of the flow in any single channel. Alternatively, it may be viewed as an instantaneous 'snapshot' of the flow in the entire rotor (ignoring the channel walls), with the rotor 'unwrapped' or developed. The vertical axis may represent time $(t)$ or circumferential location $(\theta)$. Figures 3 and 4 are simplified wave diagrams for generic shock-ignition and deflagration modes for a premixed charge. If the inlet temperature and velocity are sufficiently high, the mixture may react almost instantly in a thin reaction front immediately following the shock, thus forming a detonation (Figure 3). With lower post-compression temperature, reaction does not occur until deflagration is ignited by a spark or other means, possibly from each end, and propagates through the mixture (Figure 4). An intermediate or transitional mode may be possible, where shock-induced reactions and flame front propagation are both important. With successful ignition in either mode, the reaction will energize the stopping shock through pressure waves, and further accelerate the reaction front. 
In Figures 3 and 4 the hot gas present in the channel from the previous cycle is shown to be completely exhausted so that the contact surface (dashed line) between the exhaust gas and the fresh charge goes all the way across the length of the channel. Such complete purging is not possible in a simple 2-port wave rotor intended to produce a pressure gain such that the exhaust port is at a higher pressure than the inlet port. Therefore, the wave diagram in Figure 4 should be modified to show only partial scavenging. As a consequence, the right end wall cannot be the location of an ignition source; instead, the hot gas remaining in the channel may be used for ignition (subject to the avoidance of flashback as discussed in the next section). The purging limitation does not apply if combustion gas is extracted from the wave rotor at two pressure levels, as in Figure 3, since the second exhaust port can then be a lower pressure than the inlet port. Also, these considerations are independent of the particular modes of on-rotor combustion illustrated here.

\section{Premixed Autoignition and Detonation}

An important factor influencing the likely mode is the autoignition quality of the fuel, which determines whether reaction can occur due to compression temperature rise alone, without the arrival of a flame front propagated by molecular or turbulent diffusion. Autoignition involves many chemical steps. In a gaseous hydrocarbon-air mixture at a temperature around $1000-1500 \circ \mathrm{R}$, autoignition has been observed to consist of a two-stage chemical process involving a 'cool flame"16. Empirically, autoignition is usually quantified by the autoignition delay time for a particular fuel/oxidant mixture at given temperature and pressure conditions. The chemical autoignition time varies among common hydrocarbon fuels by about an order of magnitude at fixed conditions. Also, the presence of small amounts of certain compounds (such as octane boosters in gasoline) can strongly affect autoignition in otherwise identical compositions.

Autoignition delay times have been measured in a variety of experimental reactors, including rapid compression machines ${ }^{16}$, shock tubes ${ }^{17}$, combustion bombs, and continuous plug flow ducts ${ }^{18,19}$. The values reported vary significantly, even under similar conditions, and there is disagreement about the relative influence of reaction variables (such as stoichiometry). Investigators acknowledge that ignition delay data need to be interpreted carefully in the light of fuel specifications, experimental apparatus, and autoignition detection criteria. A sample of compiled data is presented in Figure 5, where it is assumed that scaling the autoignition time with the inverse of pressure allows a rough comparison among experiments over a wide range of conditions.

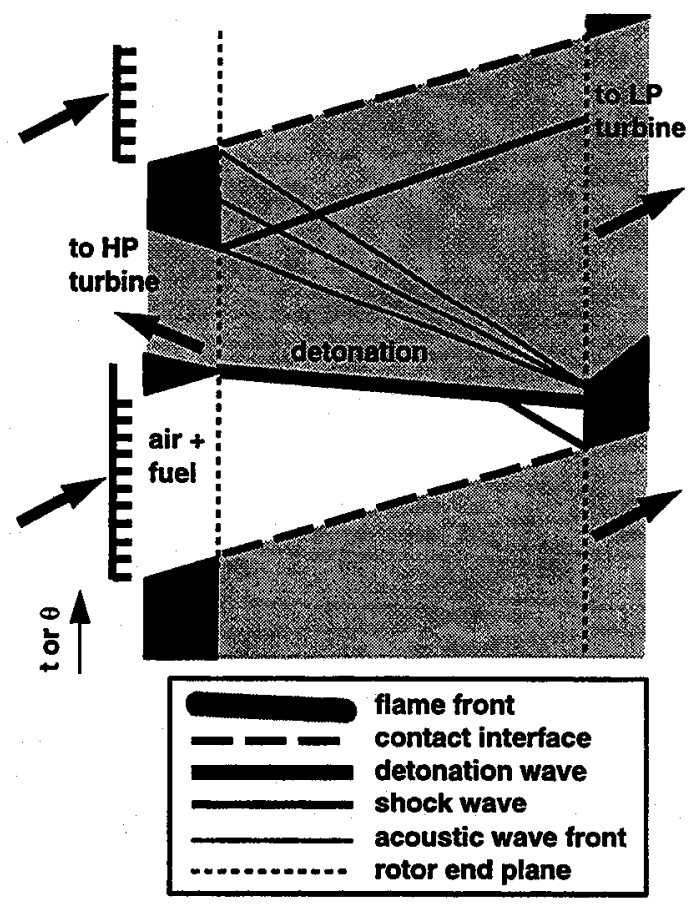

Figure 3. Simplified wave diagram for shockinduced detonation mode

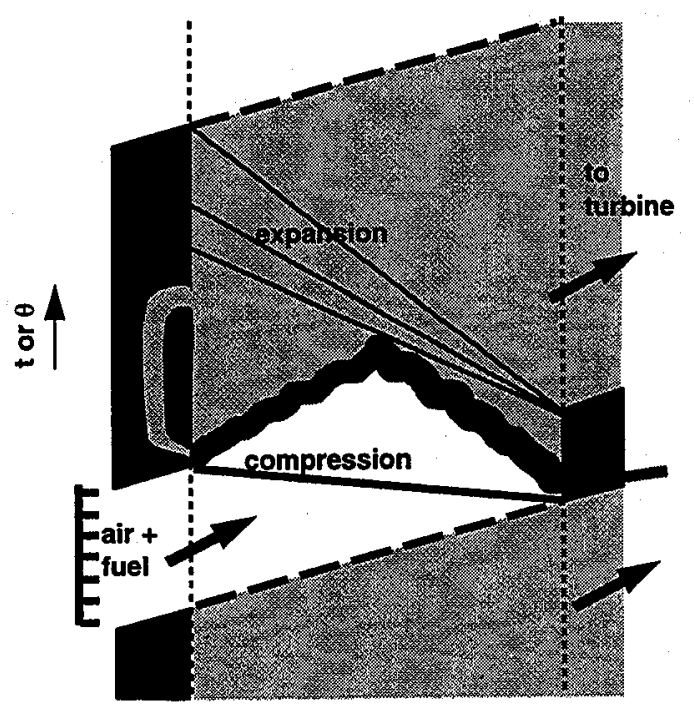

Figure 4. Simplified wave diagram for energizedignition flame propagation mode 
Referring to Figure 3, if the inflow is at nearly sonic speed, the temperature will rise by a factor about 1.4 through the stopping shock. For a hydrocarbon-air mixture entering at about $1600 \circ \mathrm{R}$, the chemical induction time will drop by a factor of about $10^{2}$ upon adiabatic compression to $2250 \circ \mathrm{R}$, from perhaps a few milliseconds to one-hundredth of a millisecond. In comparison, the acoustic transit time will be about half a millisecond for a 1 foot long channel. For these conditions it may be reasonable to assume nearly instantaneous reaction behind the shock front to form equilibrium products. Otherwise, if the postcompression temperature is below about $2000 \circ R$, the chemical time scale will be finite relative to the acoustic time scale and must be quantified. For much lower temperature (below about $1000 \circ \mathrm{R}$ ) autoignition reactions are negligible for most hydrocarbon fuels.

Note that from the reference of the unreacted mixture, the stopping end plate is equivalent to a suddenly started piston. The velocity of the gas relative to the plate, and the enthalpy of reaction, together determine whether an eventual steady-state wave (if formed) would correspond to an overdriven detonation, a Chapman-Jouguet (C-J) detonation, or no detonation. C-J detonation speeds for mixtures of propane and hydrogen with air for various conditions are given in Table 2 to illustrate the reaction speed.

The disadvantage of the detonation mode is that the wave rotor channels have to be structurally and thermally capable of handling the large pressure pulse and high speed hot gas flow behind the detonation. The pressure pulse could be exploited to drive a high pressure turbine and obtain improved performance. Note also that the duration of the high heat load is very short, and the actual wall temperature will depend on the entire cycle of hot and cold flow. Nonetheless, the weight and cost of a robust rotor may be excessive. The other drawback of relying on this mode is the uncertainty related to the temperature and composition sensitivity of autoignition already discussed. When the inlet temperature is too low for consistent and rapid autoignition, for instance at startup, an alternative ignition method is required.

An issue that concerns any premixed mode, particularly with high inlet temperatures, is premature ignition and flashback. Each channel that is rotated into contact with the intake port contains a source of ignition in the residual hot gas, albeit expanded to a relatively low temperature. If ignition by this means is sufficiently delayed so that the intake process is completed before a flame can travel upstream of the inlet plane, there is no danger. One way to avoid pre-ignition is to arrange the injection of fuel in the intake such that there is no fuel near the opening side wall of the port, thus creating an inert air buffer zone between the combustible mixture and the residual gas in the channel. The valving action of the wave rotor then naturally separates the main combustion event from the intake port. But inadequate seals may still cause premature ignition by hot gas leaking from the casing through the gap between the end wall and the spinning rotor. The hot channel walls may also potentially serve to cause ignition of the inflowing mixture. (The temperature of the walls will equilibrate somewhere between the high and low gas temperatures such that there is no net heat transfer over a complete cycle.) With sufficiently high inlet velocity, however, the high strain rate in the wall boundary layer will prevent flame stabilization. It is appropriate to point out here that all combustion which occurs before confinement and pressurization contributes absolutely no benefit from taking place in a wave rotor.

Table 2. Equilibrium C-J Detonation Speeds (ft/s)

\begin{tabular}{lllll}
\hline \hline \multirow{2}{*}{$\begin{array}{l}\text { Mixture } \rightarrow \\
\text { Equiv, ratio } \rightarrow\end{array}$} & \multicolumn{2}{c}{$\mathrm{H}_{2} /$ Air } & \multicolumn{2}{c}{$\mathrm{C}_{3} \mathrm{H}_{8} /$ Air } \\
Initial condition $\downarrow$ & 1.0 & 0.5 & 1.0 & 0.5 \\
\cline { 2 - 5 } $536 \circ \mathrm{R}, 1 \mathrm{~atm}$ & 6460 & 5280 & 5910 & 4890 \\
$1350 \circ \mathrm{R}, 1 \mathrm{~atm}$ & 6270 & 5320 & 5810 & 5020 \\
$1350 \circ \mathrm{R}, 20 \mathrm{~atm}$ & 8200 & 7050 & 7610 & 6660 \\
\hline
\end{tabular}

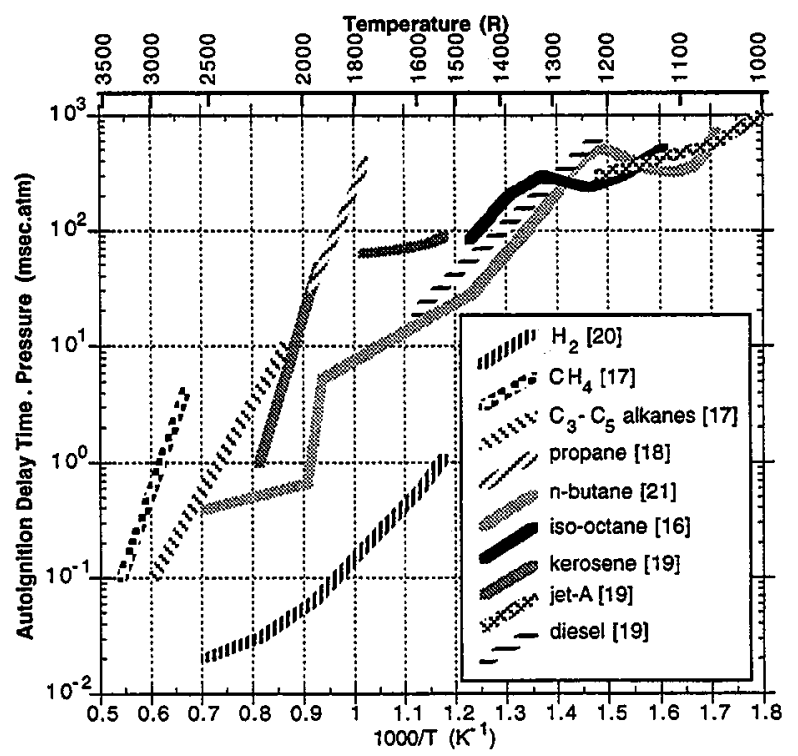

Figure 5. Autoignition delay for common fuels 


\section{Premixed Deflagration}

Turbulent flame propagation is necessary for fast burn in this mode, just as it is in the SI engine. For very narrow channels, turbulence levels may be low and heat losses significant. Therefore relatively wide channels are desirable. Sources of turbulence generation in the gas prior to being on board include the upstream compressor, ducting, fuel injection, and the opening process. Additional turbulence could be generated by a screen of appropriate mesh-size, if necessary.

As the flow passes into the channels, the turbulent kinetic energy will be distributed into length scales no larger than the characteristic channel transverse dimension (b). After coming on board, the turbulence will be affected by the compression or shock wave which stops the main flow, as well as decay with the passage of time until combustion is accomplished. Since ignition can occur as soon as the inlet closes this delay time is short. In contrast, reciprocating engine intake turbulence decays considerably during piston compression, and various means (squish, swirl, tumble) are employed to enhance turbulence.

If the turbulence intensity (root mean square of velocity fluctuations, $u^{\prime}$ ) is known, and the characteristic lengthscale of turbulent eddies is assumed equal to $\mathrm{b}$, their characteristic timescale will be $b / u^{\prime}$; this is a measure of their rate of decay. Using the intake duration $t_{i}$ as a measure of the decay time, the extent of decay can be characterized by the number of eddy rotations $n_{d}=t_{i} u^{\prime} / b$.

For small inlet Mach no. $M_{i}$, it can easily be shown that $\mathrm{n}_{\mathrm{d}} \simeq\left(\mathrm{u}^{\prime} / \mathrm{U}_{\mathrm{i}}\right)\left(\mathrm{L}_{\mathrm{i}} / \mathrm{b}\right)\left(1+\mathrm{M}_{\mathrm{i}}\right)$, where $\mathrm{L}_{\mathrm{i}}$ is the filled length of the channel (which may be less than the total length) and $U_{i}$ is the inlet velocity. For typical values of $\mathrm{L}_{\mathrm{i}} / \mathrm{b}=10, \mathrm{u}^{\prime} / \mathrm{U}_{\mathrm{i}}=0.1, \mathrm{M}_{\mathrm{i}}=0.3$, there is about one rotation and thus little decay.

Turbulent combustion can occur in a variety of regimes ranging from wrinkled laminar flames to distributed combustion. When a propagating flame can be defined, turbulent flame speed (s) depends on both turbulence properties and chemical kinetics. Investigators have attempted to express it as a function of the laminar flame speed $\left(s_{1}\right)$ and $u^{\prime}$. Measurements of $s_{t}$ in some experiments [reviewed by Heywood $^{22}$ ] indicate that $\mathrm{s}_{\mathrm{t}}$ is about equal to $\mathrm{u}^{\prime}$ for moderate levels of turbulence up to twenty times $s_{1}$. If the inlet Mach number is 0.3 and the ratio $u^{\prime} / U_{i}$ is
0.1 , the effective flame speed may be about $3 \%$ of the acoustic speed at inlet conditions. Although increasing the relative turbulence intensity is expected to help boost the flame speed, there is little data about flame propagation at very high intensities.

Ignition of a premixed gas could be by a spark, laser, recirculated or residual hot gas, or other means. In most cases there will be an ignition delay time during which an initial flame kernel develops. The combustion rate will be governed by laminar flame kinetics until the kernel reaches the size of the turbulent eddies. Multiple or distributed ignition sites would reduce the combustion time. Recirculation of high pressure combustion gas from leading channels via a passage in the end wall (as illustrated in Figure 4) can be used to provide high-speed penetrating jets of hot gas; thus high turbulence, reduced ignition delay, and fast reaction will be achieved by this means. Ignition by residual gas in the channel can be utilized only if there is a natural ignition delay which can prevent pressure loss and flashback, and if it is not precluded by buffering to avoid flashback (as discussed in the last section). It would be fortuitous if residual gas ignition can be managed and timed correctly over the range of operation of the engine.

The turbine inlet temperature limitation usually necessitates an overall fuel-air ratio that is considerably leaner than stoichiometric, with typical equivalence ratios in the range of 0.3 to 0.4 . This creates a concern whether such a mixture can support ignition and flame, particularly for low inlet temperatures. Lean-burn IC engines require charge stratification for reliable ignition, with the mixture near the spark being nearly stoichiometric. The spark is often located in a fuel-enriched 'pre-chamber' which discharges a torch of hot flame into the main chamber. The laminar flame speed and the minimum ignition energy for successful ignition both depend strongly on stoichiometry. The wave rotor charge can be similarly stratified by non-uniform fuel injection, but this will result in a temperature nonuniformity in the outflow to the turbine. The usual non-uniformity in outflow velocity will aid in homogenization if there is sufficient residence time in a downstream mixing region, but this issue will have to be considered in more depth. An on-axis wave rotor will present circumferential non-uniformity to the turbine.

Another important issue in this mode is that autoignition can occur in the end gas ahead of the flame due to combustion-induced compression of the 
unburnt mixture. Some pre-combustion reactions will normally occur as the temperature rises. If these reactions lead to autoignition before the flame arrives the concerns raised about the detonation mode also apply here. It may be necessary to use a relatively 'high octane' fuel to avoid autoignition. However, this concern will be mitigated for lean mixtures in the end gas.

\section{Non-premixed Compression Ignition}

The potential problems with premixing are uncontrolled autoignition and detonation, flashback, and ignition failure for lean mixtures. Combustion could be accomplished rapidly without complete premixing if (a) inlet temperature is sufficiently high that physical and chemical ignition delay time is very short, and (b) turbulent mixing is strong during combustion.

The non-premixed mode is similar to diesel IC engine combustion. Heat release profiles in diesel engines show that combustion occurs in two phases ${ }^{22}$. The first is rapid combustion of the fuel and air that mixed during the ignition delay period. The second phase is mixing-controlled and usually represents the bulk of the fuel consumption. The time to completion is therefore effectively determined by the turbulent mixing timescale, which normally exceeds the kinetic timescale. Similar behavior is expected in the wave rotor.

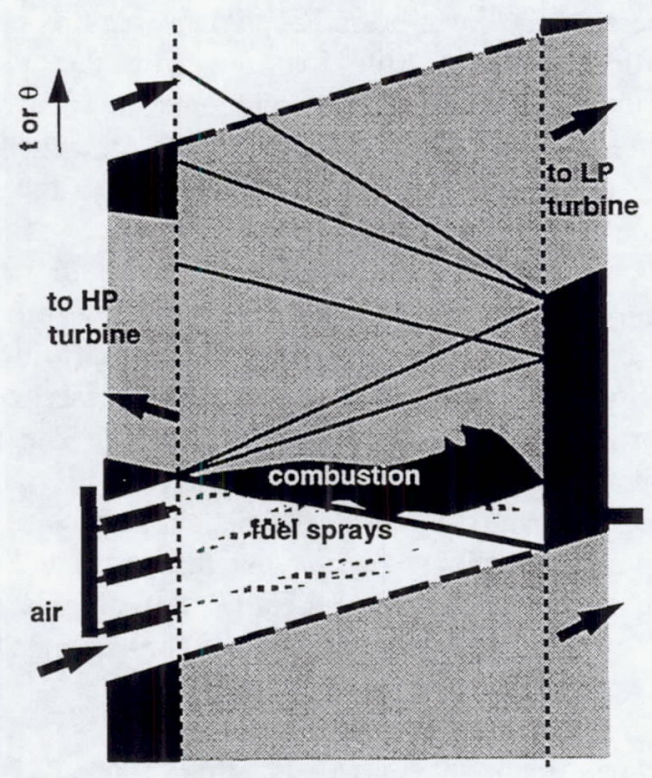

Figure 6. Simplified wave diagram for nonpremixed mode
Typical high-speed diesel sprays have initial injection velocity over $300 \mathrm{ft} / \mathrm{s}$ and can penetrate over several inches, but would take many milliseconds to do so if initiated only after the air comes to rest in the channel. To fully utilize the charge air and obtain good mixing, fuel injection will have to commence during air intake and multiple injectors may be needed. A possible wave diagram for non-premixed combustion in given in Figure 6. With inlet port injection, fuel distribution is accomplished by the flow of air rather than by spray penetration, but high pressure injection is still necessary for good atomization of liquid fuel. A likely design for port injection is a rail-type injector with plain orifices. Swirl orifices will not be useful unless placed some distance upstream of the inlet plane. Admittedly, the distinction from premixed combustion can become blurred if the number of inlet injector locations is large.

The autoignition delay time with most hydrocarbon fuels will be below one millisecond if the temperature exceeds $1800 \circ \mathrm{R}$ and the pressure is over $30 \mathrm{~atm}$ (Figure 5). For liquid fuels with high pressure injection and good atomization the physical component of the delay time is usually a small fraction. This is the time for a small amount of the fuel to evaporate and mix with air before chemical reactions can commence. The remaining fuel continues to evaporate and burn during the mixing phase of combustion.

The sources of turbulence in the mixture include the air turbulence before and during intake, as discussed for the premixed deflagration mode, as well as the high speed fuel jet. Air turbulence in CI piston engines is subject to the same limitations and decay as discussed for SI engines. The total burn duration in high speed diesels can be several milliseconds ${ }^{22}$. In the wave rotor, the combustion time will be comparable to the characteristic turbulence timescale, which can be estimated from the turbulence intensity and the characteristic lengthscale. No significant turbulence decay is expected if autoignition is fast.

\section{EXAMPLE DESIGN CASES}

Two specific applications to gas turbines engines will be considered. This exercise is intended to illustrate some of the issues discussed above, but is limited to the particular cases considered. Based on an experimentally validated CFD code developed recently at the NASA Lewis Research Center, Wilson 
and Paxson ${ }^{7}$ have presented optimized wave rotor designs for 4-port external combustion topping cycles for engine sizes from 4 to $400 \mathrm{lb} / \mathrm{sec}$ core flow capacity. The equivalent 2-port internal combustion wave rotors, which would have the same inflow and outflow states, are examined here for two of these designs. The overall performance of the topped engines depend only on these states, and thus would be identical, whether the combustion is internal or external. Although the wave rotor design features optimized for external combustion may not all be appropriate for on-board combustion, as many as possible are retained. The fuel is assumed to be a hydrocarbon similar to jet fuel.

Table 3 indicates the relevant data for these designs. The 4-port wave rotor cycles for both designs are virtually identical when non-dimensionalized with respect to their inlet states. Their common wave diagram, shown in Figure 7, shows that the hot gas present in the channel is not completely exhausted but a fraction of it is recirculated to the external combustor. The reason is the same as that discussed for the 2-port internal combustion rotor - that complete scavenging is inconsistent with pressure gain. Only $65 \%$ of the hot gas in the channel at state ' $\mathrm{f}$ ' is exhausted; the mass flow through the combustor is increased by a factor of 1.55 due to the recirculation of the remainder. Thus the channel is only partially filled with fresh air for compression in the wave rotor. Accounting for temperature differences and pressure changes, the fresh charge (state 'i') will come to occupy $45 \%$ of the length of the channel, if unreacted after the ram compression wave.

Figure 8 is a wave diagram for a 2-port wave rotor using internal combustion, which replicates the inlet and exhaust flows of the 4-port wave rotor. The strengths of the inlet compression wave and the exhaust expansion wave are also replicated; as are therefore the states marked ' $\mathrm{i}$ ' and ' $\mathrm{f}$ ' which now represent the initial and final states of the internal combustion process. Although the total volume of gas remains constant, the fresh charge expands in volume by a factor of 1.4 during combustion while the pressure increases by a factor of 1.7 . Neglecting irreversibility during the recompression of the residual gas, the final states of the fresh and residual gases are indistinguishable.

The absolute temperatures of the initial states in the two engine designs differ widely, dictating different combustion modes as discussed below.
Table 3. Engine and wave rotor design data ${ }^{7,23}$

\begin{tabular}{|c|c|c|}
\hline Small 1 & Engine & Large Engine \\
\hline \multicolumn{3}{|l|}{ Base Engine } \\
\hline Core Mass Flow (lb/sec) & 4 & 400 \\
\hline Shaft Compression Ratio & 7 & 40 \\
\hline Turbine Inlet Temperature $(\circ \mathrm{R})$ & 2400 & 3200 \\
\hline Compressor Discharge Temp. $\left({ }^{\circ} \mathrm{R}\right)$ & 1040 & 1680 \\
\hline Core Air to Fuel Mass Ratio & 45.8 & 38.6 \\
\hline \multicolumn{3}{|l|}{ Four-port wave rotor } \\
\hline Rotor Diameter, Length (in.) & 6,6 & 24,12 \\
\hline Channel Height, Width (in.) & $0.637,0.30$ & $4.51,0.38$ \\
\hline Rotor Speed (rpm) & 15600 & 4200 \\
\hline Wave cycles per revolution & 2 & 4 \\
\hline Wave cycle period (ms) & 1.92 & 3.57 \\
\hline Relative Inlet Velocity (ft/s) & 700 & 900 \\
\hline \multicolumn{3}{|l|}{ Performance of topped engine } \\
\hline Pressure Gain in wave rotor & 1.232 & 1.204 \\
\hline$\%$ Increase in core specific power & 23 & 8.7 \\
\hline$\%$ Decrease in SFC & 18.8 & 8.0 \\
\hline \multicolumn{3}{|c|}{ Combustion initial and final states } \\
\hline$T_{i}(\circ R)$ & 1150 & 1865 \\
\hline $\mathrm{p}_{\mathrm{i}}(\mathrm{atm})$ & 9.7 & 55.2 \\
\hline $\mathrm{T}_{\mathrm{f}}(\circ \mathrm{R})$ & 2850 & 4600 \\
\hline $\mathrm{p}_{\mathrm{f}}(\mathrm{atm})$ & 16.5 & 94.4 \\
\hline
\end{tabular}

\section{Small Engine Case}

Referring to Figure 5, the autoignition delay time for the initial conditions of $1150 \circ \mathrm{R}$ and $9.7 \mathrm{~atm}$ is about $50 \mathrm{~ms}$ for most hydrocarbon fuels, whereas the intake process takes only about $0.5 \mathrm{~ms}$. Therefore the only feasible mode of combustion is premixed deflagration, ignited by a spark or hot gas jet at the left end wall, and possibly also by the residual gas on the right. Recirculated or residual hot gas from previous combustion at the same overall equivalence ratio of 0.3 will have a temperature of $2530 \circ \mathrm{R}$.

Suppose the charge near the left end wall is stoichiometric to ensure ignition and minimize the ignition delay. For the above initial conditions, the laminar flame speed is estimated to be $3.5 \mathrm{ft} / \mathrm{sec}$ for gasoline and similar fuels. If the characteristic turbulence length scale is taken equal to the channel width ( 0.3 in.) the spark ignition delay time is estimated to be $7 \mathrm{~ms}$, which is clearly unacceptable if the total wave cycle time is to be limited to about the same as for the 4-port rotor. Although this is a crude estimate, it is a fairly certain indication that a much 
stronger source of ignition is desirable, such as a jet of recirculated hot gas.

If the turbulence kinetic energy in the inlet flow is assumed to be about $5 \%$ of the total kinetic energy (which corresponds to a drop in total pressure of about $1 \%$ ), then $\mathrm{u}^{\prime}=150 \mathrm{ft} / \mathrm{s}$. With a single turbulent flame travelling at this speed for the distance about half the length of the rotor which contains combustible mixture, the time for combustion is about $1.6 \mathrm{~ms}$. This would put the total wave cycle time at only slightly over that for the corresponding external combustion design. Even if this intensity of turbulence could be provided, there remains some question whether the extrapolation of flame speed to these conditions is valid. There is a critical need for good experimental data to support or modify this assessment.

The combustion time could be cut in half if a second flame front was initiated at the right from the hot residual gas, but the danger of premature ignition or flashback may preclude it. Again, only experiments can resolve the uncertainty about the complex interaction between turbulence, ignition chemistry, and wave dynamics that control this possibility.

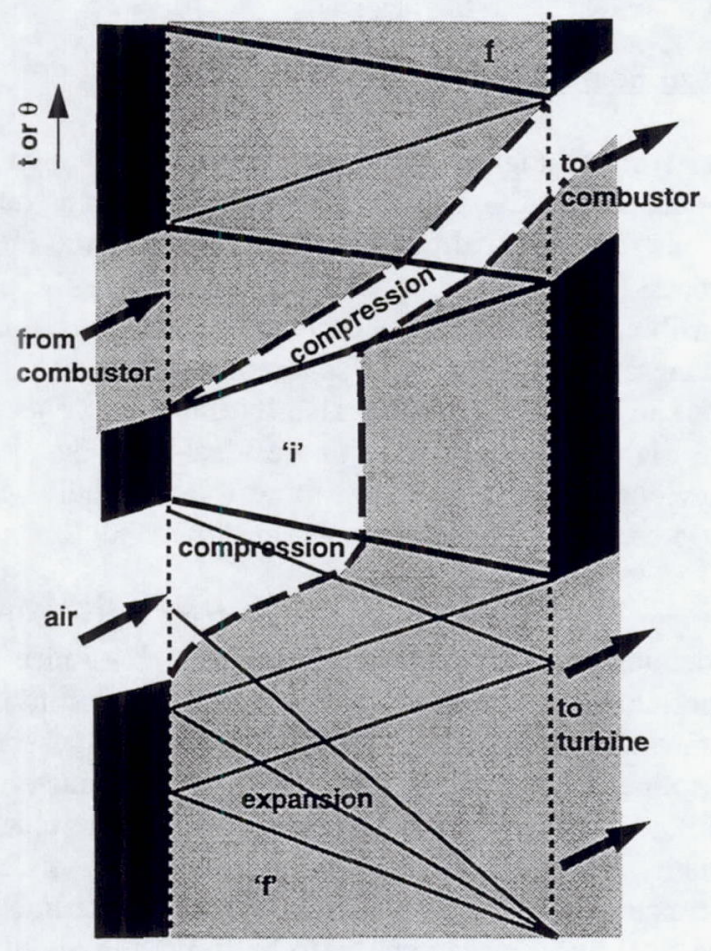

Figure 7. Wave diagram for 4-port topping cycle

\section{$\underline{\text { Large Engine Case }}$}

For the post-intake conditions of 55.2 atm and $1865 \circ \mathrm{R}$, the autoignition data in Figure 5 exhibit considerable variation, and the autoignition delay time for hydrocarbon fuels ranges from $0.2 \mathrm{~ms}$ to $2 \mathrm{~ms}$; for jet fuel the delay time will likely be closer to the shorter limit. The intake duration is about $1 \mathrm{~ms}$ and the intake Mach number in this design (about 0.45 relative to the moving channel) results in a temperature rise of about $200 \circ \mathrm{R}$ across the stopping compression wave. Given the uncertainty in the data, there is a risk of autoignition in the intake. Therefore it is preferable to avoid premixing, thus also preventing detonation. A number of stationary fuel injectors, perhaps three or four placed close to the intake plane, would deliver fuel into the channels at evenly spaced locations in the charge, but avoiding the leading zone that touches the residual gas. Since the channel is not fully purged, fuel injection can only take place at the inlet end.

If the turbulence kinetic energy in the inlet flow is again assumed to be $5 \%$ of the total kinetic energy, and the characteristic turbulence length scale is assumed equal to the channel width, the characteristic turbulence timescale will be about $0.2 \mathrm{~ms}$. In that case, it appears feasible to complete ignition and combustion in the available $2 \mathrm{~ms}$ or less, in order to keep the total cycle time the same as with external combustion.

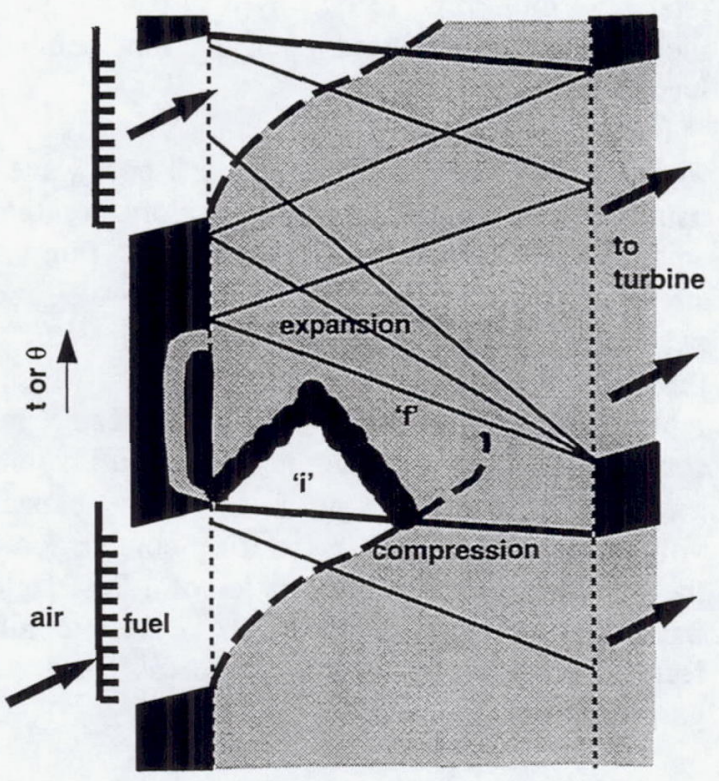

Figure 8. Wave Diagram for equivalent internal combustion cycle 


\section{OTHER ISSUES}

Some additional issues that may be important in the design of a combustion wave rotor are mentioned here.

1. Compared to the external combustion cycle, the on-rotor combustion and gas dynamics are closely and dynamically coupled. This creates the possibility of cycle-to-cycle variability and oscillations whose stability behavior is unknown at present. For instance, an increase in the amount of fuel in one cycle will result in a higher combustion pressure, and thus reduce the mass of air taken in the next cycle. The growth or decay of such a disturbance will partly depend on how the fueling is controlled.

2. In the wave cycle of Figure 8, the fresh charge does not completely fill the channel. Therefore the cooling effect of the cold charge will be experienced only by one end of the rotor, unless multiple cycles are completed in a single rotation with the inlet and exhaust port located at alternating ends of the rotor. For example, the inlet on the left could be followed (after combustion) by an exhaust port on the left, and the inlet for the next cycle would then be on the right. This reverse flow arrangement would leave a buffer layer of gas that always remains in the rotor if there is perfect symmetry. Other arrangements are possible that would also provide even cooling.

3. Only a single design operating point is considered in the examples discussed. In reality mixture conditions may vary considerably over the operating range of the engines. In-rotor ignition and combustion may be more sensitive to these variations than conventional combustion systems. Consider that the wave rotor inlet temperature in an aircraft gas turbine may differ markedly between sea-level takeoff and descent from altitude. Guaranteeing ignition at all conditions may require some form of fuel staging.

It is evident that the concept of combustion in a wave rotor presents some unique challenges, but there may also be many unexplored ideas and possibilities for design.

\section{CONCLUSIONS}

Combustion within the channels of a wave rotor is a promising means of obtaining pressure gain during heat addition in a gas turbine engine. The feasibilities of three modes of combustion were evaluated: premixed autoignition/detonation, premixed deflagration, and non-premixed compression ignition.

Premixed deflagration and non-premixed combustion will require strong turbulence for completion of combustion in a reasonable time in the wave rotor. If sufficient turbulence is not generated by the upstream and intake processes, additional turbulence generation means will be necessary. Little decay of turbulence is expected after the flow enters the channel.

Premixed and non-premixed autoignition modes will require inlet temperatures in excess of about $1500 \circ \mathrm{R}$ for reliable ignition with most hydrocarbon fuels; otherwise, a supplementary ignition method must be provided. A detonation wave is possible with premixed gas at high inlet temperature, and will result in extremely short reaction time, but it may complicate the mechanical design of the rotor. If a non-hydrocarbon fuel such as hydrogen is to be used, the conclusions regarding ignition will be different.

Examples of combustion mode selection are presented for two core engine applications that had been previously designed with equivalent 4-port wave rotor topping cycles using external combustion. The first engine has a mass flow of $4 \mathrm{lb} / \mathrm{sec}$ and a pressure ratio of 7 . For this engine the premixed deflagration mode is recommended, and a high energy ignition source such as a jet of hot recirculated gas is required. The second engine has a $400 \mathrm{lb} / \mathrm{s}$ core and a pressure ratio of 40 . Because of the high inlet temperature, non-premixed autoignited combustion is possible. It is estimated that combustion in each engine can be completed in a reasonable time if the turbulent kinetic energy in the inflow exceeds about $5 \%$ of the total kinetic energy.

\section{$\underline{\text { ACKNOWLEDGEMENTS }}$}

This work was performed while the author held a National Research Council - NASA Lewis Research Center Research Associateship, with Dr. L. Bober serving as Advisor. The comments of $\mathrm{L}$. Larosiliere and $\mathrm{J}$. Wilson are appreciated.

\section{REFERENCES}

1. Foa, J.V., 1960, Elements of Flight Propulsion, John Wiley \& Sons.

2. Kentfield, J.A.C., and O'Blenes, M., 'Methods of Achieving a Combustion-Driven Pressure Gain in 
Gas Turbines, ASME J. Eng. Gas Turbines \& Power, vol.110, p.704, 1988.

3. Goldstein, A.W., Klapproth, J.F., and Hartmann, M.J., 'Ideal Performance of Valved-Combustors and Applicability to Several Engine Types', ASME paper 57-A-102.

4. Shreeve, R.P., and Mathur, A., (ed.), Proc. of the 1985 ONR/NAVAIR Wave Rotor Research and Technology Workshop. Naval Postgraduate School, Monterey, California. May 1985.

5. M. Berchtold, in Ref. 4, p. 50.

6. Carpenter, J.E., Research Trends, 2nd Quarter 1963, Cornell Aero. Lab., Buffalo, NY.

7. Wilson, J., and Paxson, D.E., 'Optimization of Wave Rotors for Use as Gas Turbine Topping Cycles', SAE paper 951411.

8. E.L. Resler, Jr., J.C. Mocsari, and M.R. Nalim, 'Analytic Design Methods for Wave Rotor Cycles', AlAA J. Propulsion and Power, 10:5, p.683, 1994.

9. E. Zauner, Y.-P. Chyou, F. Walraven, and R. Althaus, (1993), 'Gas Turbine Topping Stage based on Energy Exchangers: Process and Performance'. ASME paper 93-GT-58.

10. Resler, E.L, Jr., 'Intake Manifold Prestratified Charge', Chem. Eng. Comm., Vol. 67, pp. 111-127, 1988.

11. Tice, J.K. and Nalim, M.R., 'Control of $\mathrm{NO}_{\mathrm{x}}$ Emissions in Gas Engines using Pre-stratified charge - Applications and Field Experience', ASME paper 88-ICE-11.

12. Nalim M.R., and Resler, E.L., Jr., 'Wave Cycle Design For Wave Rotor Gas Turbine Engines with Low NOx Emissions', ASME paper 95-GT-245. 13. Nalim, M.R., 'Wave Cycle Design for Wave Rotor Engines with Limited Nitrogen Oxide Emissions', Ph.D. Thesis, Jan. 1994, Cornell University, Ithaca, N.Y.

14. McGreevy, J.L., and Matalon, M., Combustion and Flame, 91: 213-225 (1992).

15. J.F. Clarke, Prog. Energy Combust. Sci., Vol.15, pp. 241-271, 1989.

16. Halstead, M.P., Kirsch, L.J., and Quinn, C.P., 'The Autoignition of Hydrocarbon Fuels at High Temperatures and Pressures - Fitting of a Mathematical Model', Combustion and Flame, 30: 45-60 (1977).

17. Burcat, A., Scheller, K., and Lifshitz, A., 'Shock-Tube Investigation of Comparative Ignition Delay Times for C1-C5 Alkanes', Combustion and Flame, 16:29-33 (1971).

18. Freeman, G., and Lefebvre, A.H., 'Spontaneous Ignition Characteristics of Gaseous Hydrocarbon-Air Mixtures', Combustion and Flame, 58: 153-162 (1984).
19. TeVelde, J.A. and Spadaccini, L.J., 'Autoignition Characteristics of No. 2 Diesel Fuel', NASA CR-165315, 1981.

20. Slack, M. and Grillo, A., 'Investigation of Hydrogen-Air Ignition Sensitized by Nitric Oxide and Nitrogen Dioxide', NASA CR-2896, 1977.

21. Ohta, Y., et al, ' $n$-Butane Ignition in a Wide Range of Temperatures', Progress in Astronautics and Aeronautics, v. 113, p.225 (1987).

22. Heywood, J.B., Internal Combustion Engine Fundamentals, McGraw-Hill, 1988.

23. Paxson, D.E., private communication, 1995. 
Public reporting burden for this collection of information is estimated to average 1 hour per response, including the time for reviewing instructions, searching existing data sources, gathering and maintaining the data needed, and completing and reviewing the collection of information. Send comments regarding this burden estimate or any other aspect of this collection of information, including suggestions for reducing this burden, to Washington Headquarters Services, Directorate for Information Operations and Reports, 1215 Jeller Davis Highway, Suite 1204, Arlington, VA 22202-4302, and to the Office of Management and Budget, Paperwork Reduction Project (0704-0188), Washington, DC 20503.
1. AGENCY USE ONLY (Leave blank)
2. REPORT DATE
July 1995
3. REPORT TYPE AND DATES COVERED
Technical Memorandum

4. TITLE AND SUBTITLE

5. FUNDING NUMBERS

Preliminary Assessment of Combustion Modes for Internal

Combustion Wave Rotors

6. AUTHOR(S)

WU-505-90-58

M. Razi Nalim

7. PERFORMING ORGANIZATION NAME(S) AND ADDRESS(ES)

8. PERFORMING ORGANIZATION REPORT NUMBER

National Aeronautics and Space Administration

Lewis Research Center

Cleveland, Ohio 44135-3191

E-9779

9. SPONSORING/MONITORING AGENCY NAME(S) AND ADDRESS(ES)

10. SPONSORING/MONITORING AGENCY REPORT NUMBER

National Aeronautics and Space Administration

Washington, D.C. 20546-0001

NASA TM-107000

AIAA-95-2801

11. SUPPLEMENTARY NOTES

Prepared for the 31st Joint Propulsion Conference and Exhibit cosponsored by AIAA, ASME, SAE, and ASEE, San Diego, California, July 10-12, 1995. M. Razi Nalim, National Research Council-NASA Research Associate at Lewis

Research Center. Responsible person, M. Razi Nalim, organization code 2760, (216) 433-6187.

12a. DISTRIBUTIONAVAILABILITY STATEMENT

12b. DISTRIBUTION CODE

Unclassified - Unlimited

Subject Category 07

This publication is available from the NASA Center for Aerospace Information, (301) 621-0390.

13. ABSTRACT (Maximum 200 words)

Combustion within the channels of a wave rotor is examined as a means of obtaining pressure gain during heat addition in a gas turbine engine. Several modes of combustion are considered and the factors that determine the applicability of three modes are evaluated in detail; premixed autoignition/detonation, premixed deflagration, and non-premixed compression ignition. The last two will require strong turbulence for completion of combustion in a reasonable time in the wave rotor. The compression/autoignition modes will require inlet temperatures in excess of $1500^{\circ} \mathrm{R}$ for reliable ignition with most hydrocarbon fuels; otherwise, a supplementary ignition method must be provided. Examples of combustion mode selection are presented for two core engine applications that had been previously designed with equivalent 4-port wave rotor topping cycles using external combustion.

14. SUBJECT TERMS

Combustion; Wave rotor; Pressure exchange; Pressure gain; Gas turbine; Shock wave; Internal combustion; Detonation

17. SECURTY CLASSIFICATION OF REPORT

Unclassified

18. SECURTYY CLASSIFICATION
OF THIS PAGE
Unclassified

Unclassified
19. SECURITY CLASSIFICATION OF ABSTRACT Unclassified 

National Aeronautics and

Space Administration

Lewis Research Center

21000 Brookpark Rd.

Cleveland, $\mathrm{OH}$ 44135-3191

Official Business

Penalty for Private Use $\$ 300$

POSTMASTER: If Undeliverable - Do Not Return 